\author{
УДК 621.454.3.035.5
}

Кисличная О. В., Максименко И. В., Брынза М. Б., Потапов А. М.

Государственное предприятие «Конструкторское бюро «Южное» им. М.К. Янгеля», Украина, г. Днепр

\title{
КОНСТРУКТИВНО - ТЕХНОЛОГИЧЕСКИЕ ОСОБЕННОСТИ ИЗГОТОВЛЕНИЯ ЭКСПЕРИМЕНТАЛЬНОГО СОПЛА ДЛЯ МОДЕЛЬНОГО ТВЕРДОТОПЛИВНОГО ДВИГАТЕЛЯ
}

В статье изложены технологические особенности изготовления экспериментального сопла для модельного двигателя. Рассмотрена конструкиия әкспериментального сопла. Указаны рисунки деталей и сборочных единиц. Приведены основные технологические операции изготовления. Особое внимание уделено выбору материалов и способам изготовления заготовок. Приведен сравнительный анализ испытаний сопел с различными материалами вкладыщей критического сечения. [dx.doi.org/10.29010/081.7]

Ключевые слова: экспериментальное сопло; заготовка воротника; вкладыш критического сечения; механическал обработка; сборка-склейка.

Введение

Сопло является самым теплонапряженным элементом двигателя, испытывающим теплоэрозионные нагрузки от высокоскоростного и высокотемпературного двухфазного потока. [1]

Сопло для модельного двигателя состоит из цельной металлической конструкции и теплозащиты. Его общая длина составляет 220 мм и вес 7 кг 430 г. Такие сопла применяются при малом времени работы двигателя (5,5 c).

Детали сопла по функционированию и месту расположения могут быть разделены на входную часть (корпус сопла, теплозащитная подложка, вкладыш, воротник) и выходную часть (раструб). При этом корпус сопла относится как к входной части, так и к выходной части сопла. [2]

Выбор материалов для элементов сопла определяется следующими факторами: распределением температуры вдоль базовой оси сопла во время работы двигателя, назначением и условиями работы деталей в двигателе. [1]

Материалы для сопел должны обладать жаропрочностью и жаростойкостью при температурах до $3500 K$, достаточной конструктивной прочностью, эрозионной стойкостью, минимальной массой. [1]

\section{Постановка задачи}

Для отработки технологии изготовления деталей из теплозащитных и эрозионностойких материалов, а также заряда твердого топлива Государственным предприятием «Конструкторское бюро «Южное» была спроектирована и выпущена конструкторская документация на изготовление экспериментального сопла для модельного двигателя.

На производственной базе предприятия были изготовлены экспериментальные сопла для модельных двигателей.

\section{Основная часть}

Экспериментальное сопло предназначено для отработки заряда модельного двигателя твердым топливом при температурах от -40 до +50 и проведения огневых стендовых испытаний.

Общий вид экспериментального сопла представлен на рисунке 1.

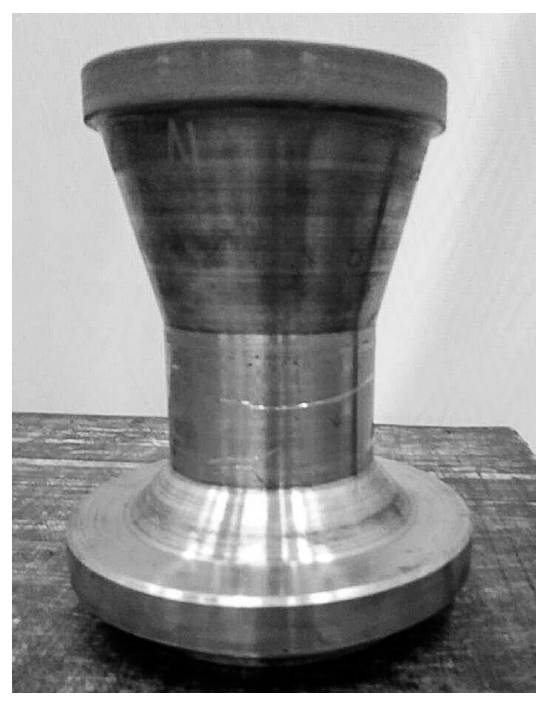

Рис. 1. Экспериментальное сопло 
Конструкция экспериментального сопла состоит из:

- Металлического корпуса сопла;

- Теплозащитной подложки;

- Вкладыша критического сечения;

- Входного воротника;

- Выходного раструба;

- Полимерной заглушки.

Для определения сравнительных характеристик материалов после огневых стендовых испытаний, а также показателей тяги было принято решение изготовить экспериментальные сопла двух видов, отличающиеся разными материалами вкладышей критического сечения.

Для первого варианта в качестве материала для изготовления заготовки вкладыша критического сечения был выбран УУКМ ЗД структуры на основе нити углеродной конструкционной и пироуплотнен (рисунок 2), а для второго варианта углерод-углеродный материал на основе углерод- ной ткани и войлока также с последующим пироуплотнением (рисунок 3 ). В таблице 1 приведены сравнительные характеристики материалов для вкладышей критического сечения.

Учитывая, что вкладыш за время работы двигателя разогревается до весьма высокой температуры, в конструкции между вкладышем и металлическим корпусом предусмотрена теплозащитная подложка, предохраняющая металлический корпус от прогара.

В качестве материала для изготовления теплозащитной подложки выбран пресс-материал на основе рубленого стекловолокна и фенольного связующего. Заготовка подложки изготовлена путем склеивания двух колец из пресс-материала эпоксидным клеем (рисунок 4).

В качестве материала для изготовления заготовки раструба выбран углеродный тканевый трикотаж. Заготовка раструба изготавливается методом намотки на жесткую металлическую оправку

Таблица 1

Сравнительные характеристики материалов для вкладышей критического сечения

\begin{tabular}{|c|c|c|}
\hline \multirow{2}{*}{ Параметр } & \multicolumn{2}{|c|}{ Материал } \\
\hline & $\begin{array}{c}\text { на основе углеродной ткани } \\
\text { и войлока } \\
\end{array}$ & $\begin{array}{c}\text { на основе нити углеродной } \\
\text { конструкционной }\end{array}$ \\
\hline Плотность, кг/м³ & 1,77 & 1,77 \\
\hline $\begin{array}{l}\text { Разрушающее напряжение при сжатии } \\
\text { (вдоль/поперек), кгс/мм² }\end{array}$ & $22,96 / 12,76$ & $15,3 / 15,3$ \\
\hline Коэффициент теплопроводности, Вт/(м·К) & $20 \div 30$ & 0,7 \\
\hline
\end{tabular}

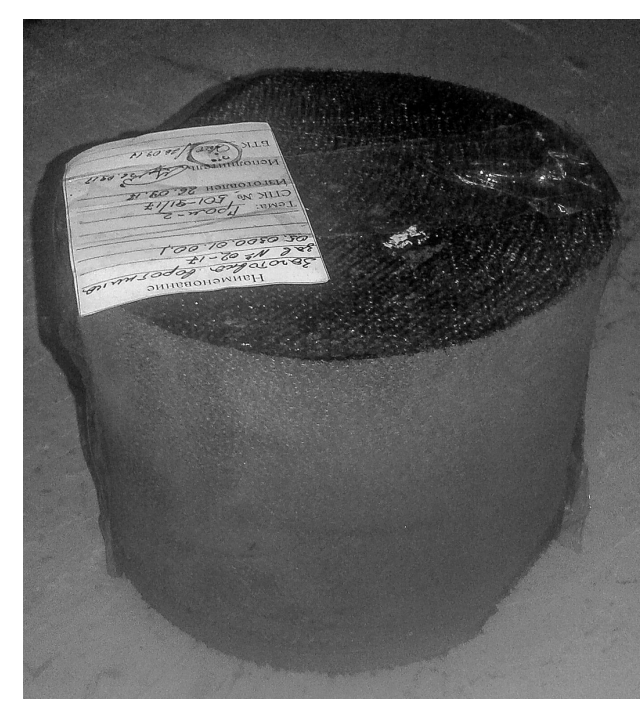

Рис. 2. Заготовка вкладыша из материала на основе нити углеродной конструкционной

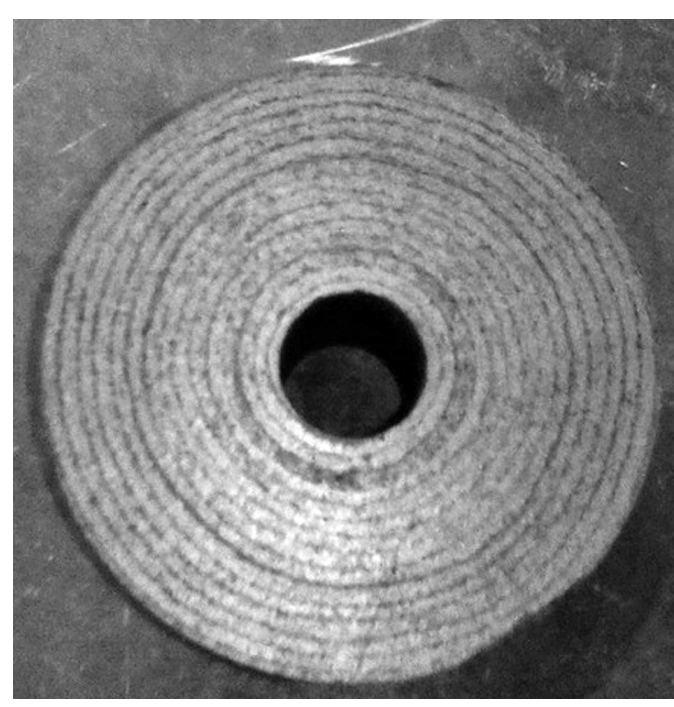

Рис. 3. Заготовка вкладыша из материала на основе углеродной ткани и войлока 


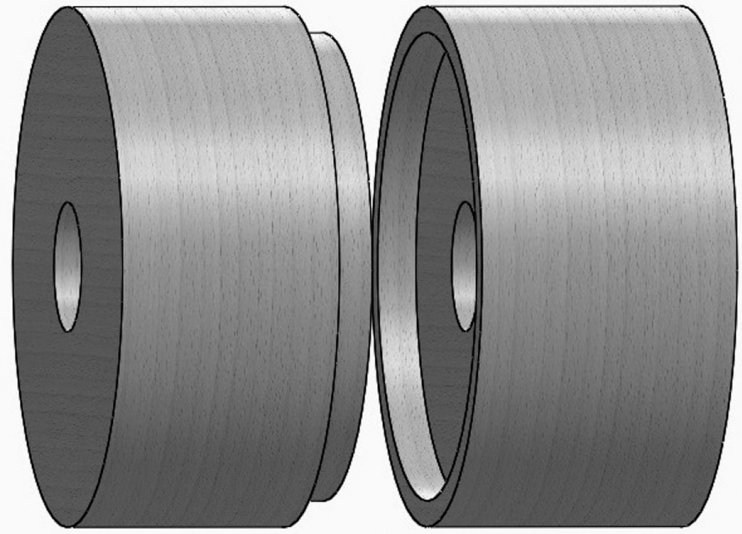

Рис. 4. Изготовление заготовки подложки

трикотажных лент, предварительно пропитанных фенольным связующим с последующим отверждением по заданному режиму (рисунок 5).

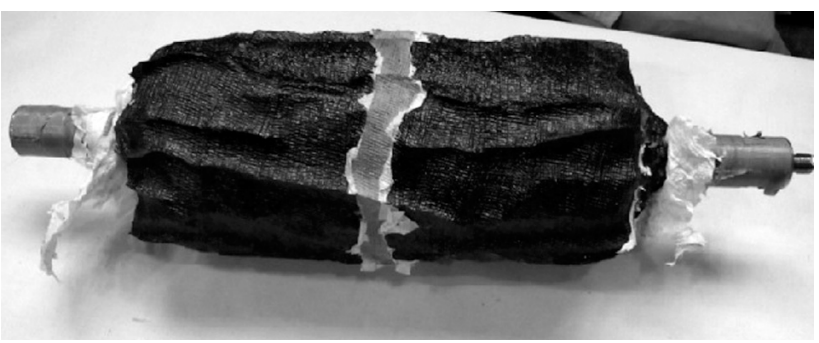

Рис. 5. Заготовка раструба на металлической оправке

Материал для изготовления заготовки воротника выбран по аналогии с изготовлением заготовки раструба - углеродный тканевый трикотаж, предварительно пропитанный фенольным связующим. Заготовку воротника изготавливают путем выкладки заготовок углеродной ткани в пресс-форму с дальнейшим формованием под высоким давлением по заданному режиму (рисунок 6).

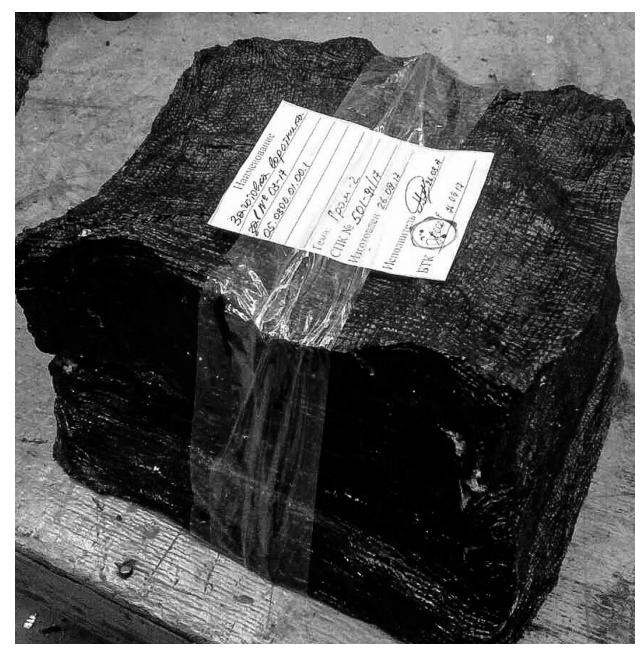

Рис. 6. Заготовка воротника
Заглушка для экспериментального сопла изготовлена из полимерных нитей на ЗД принтере. Основная ее функция защита полости выходной части сопла от попадания загрязнений и выпадения конденсата (рисунок 7).

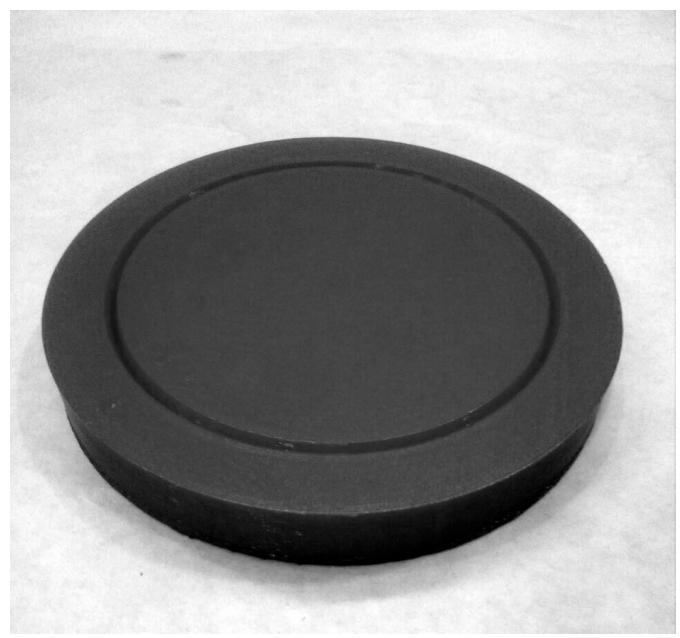

Рис. 7. Заглушка

В процессе сборки-склейки экспериментального сопла были выполнены следующие основные технологические операции:

Механическая обработка заготовки подложки (рисунок 8).

Вклейка подложки в корпус сопла с последующей механической обработкой корпуса с подложкой (рисунок 9).

Механическая обработка заготовки раструба (рисунок 10) с последующей вклейкой его в корпус с подложкой (рисунок 11) и в дальнейшем механической обработкой корпуса с раструбом.

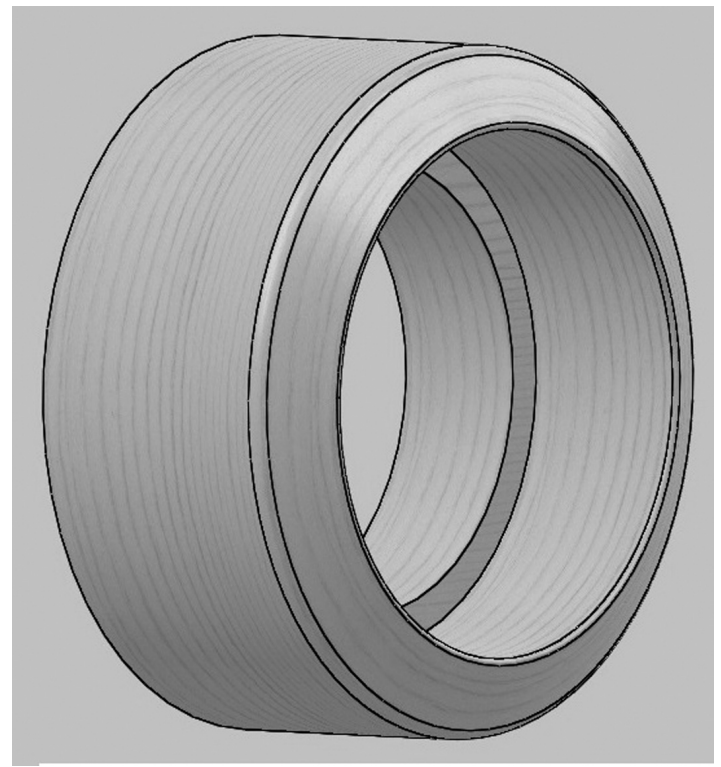

Рис. 8. Теплозащитная подложка 


\section{4/2017 ПЕхнологическиE:TC}

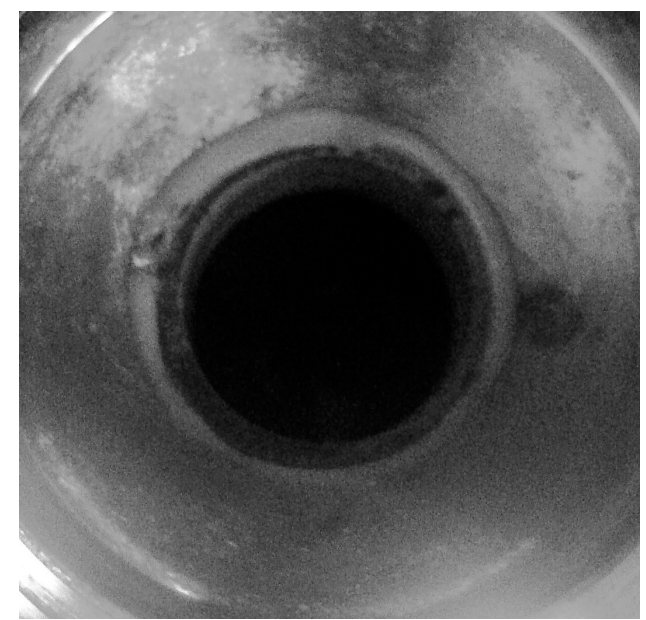

Рис. 9. Корпус с подложкой

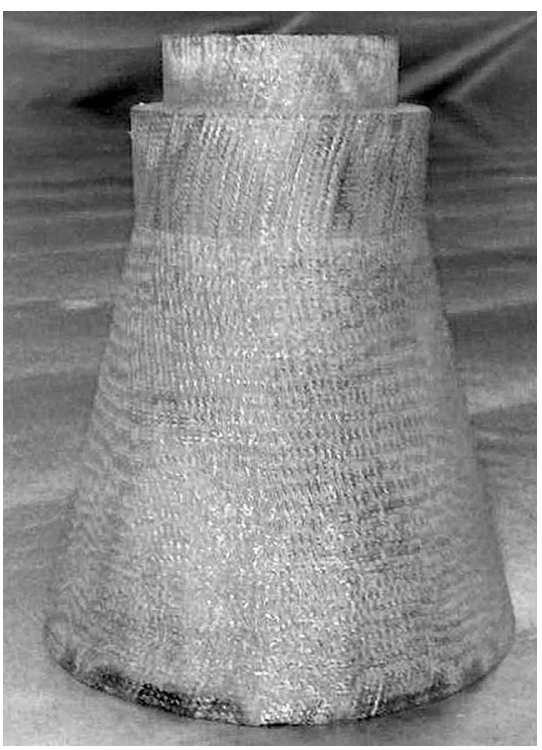

Рис. 10. Раструб

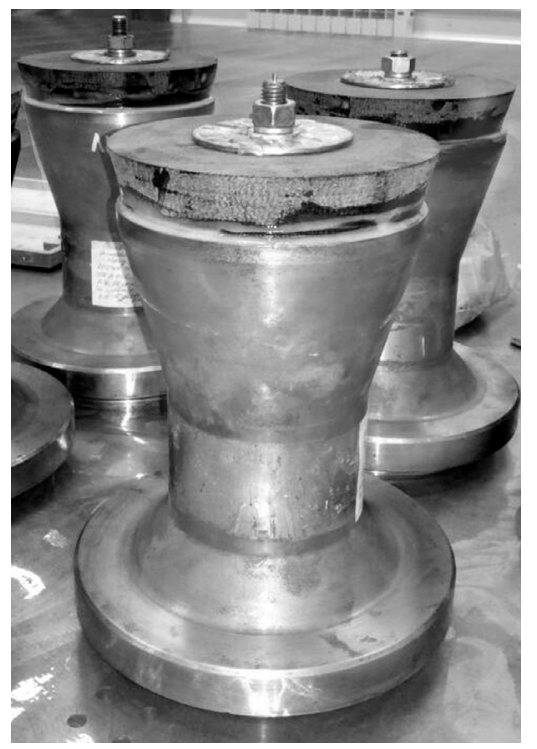

Рис. 11. Корпус с раструбом
Механическая обработка заготовки вкладыша (рисунок 12) с последующей вклейкой вкладыша в корпус с раструбом (рисунок 13) и механической обработкой корпуса с вкладышем.

Механическая обработка заготовки воротника (рисунок 14) с последующей вклейкой воротника в

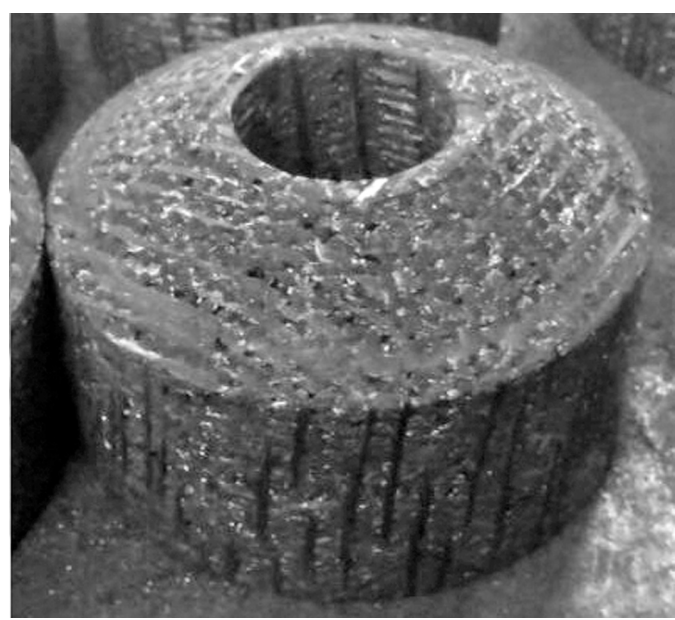

Рис. 12. Вкладыш

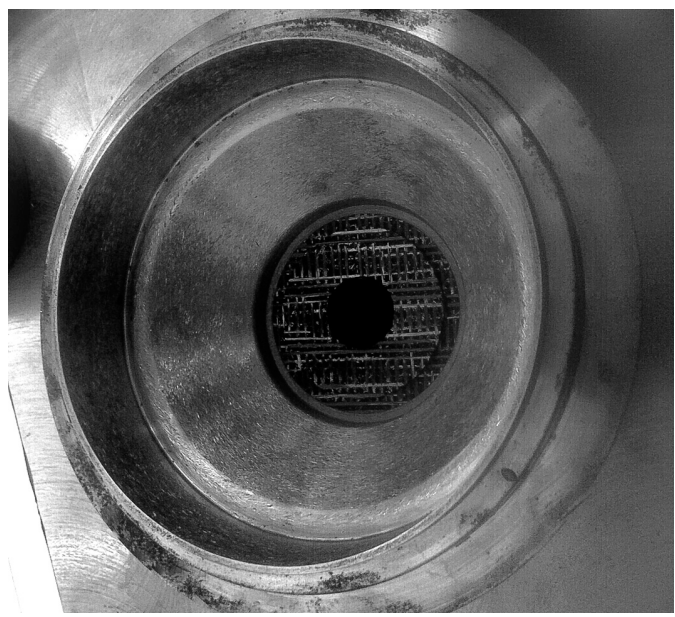

Рис. 13. Корпус с вкладышем

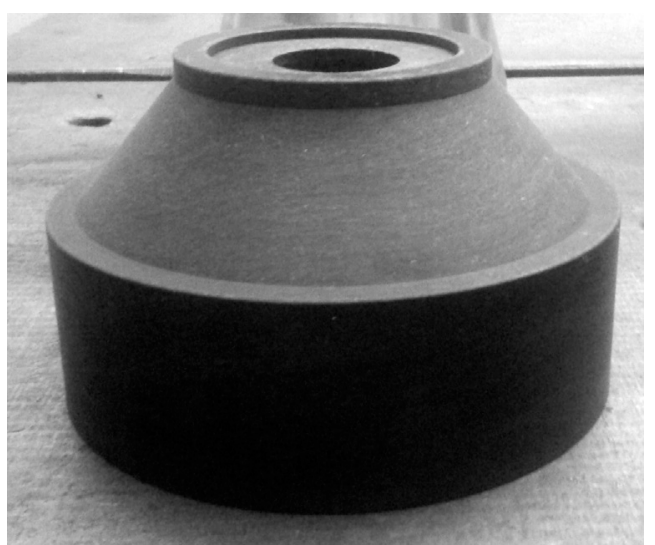

Рис. 14. Воротник 


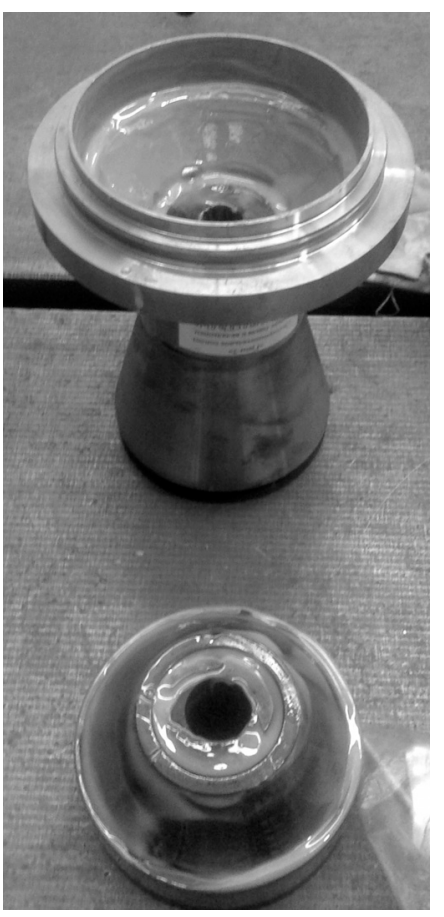

Рис. 15. Вклейка воротника

корпус с вкладышем (рисунок 15) и механической обработкой внутреннего теплозащитного покрытия сопла (рисунок 16).

Перед склейкой деталей и сборочных единиц предварительно проводилась «сухая» сборка-примерка, в результате которой определялись фактические величины зазоров между сопрягаемыми поверхностями в четырех плоскостях стабилизации. В дальнейшем поверхности деталей и сборочных единиц обязательно зачищались и обезжиривались. На подготовленные склеиваемые поверхности тонким слоем наносился эпоксидный клей и производилась склейка деталей и сборочных единиц.

Механическая обработка деталей и сборочных единиц экспериментального сопла осуществлялась на токарном универсальном станке.

При изготовлении экспериментального сопла были выдержаны его основные параметры, такие как:

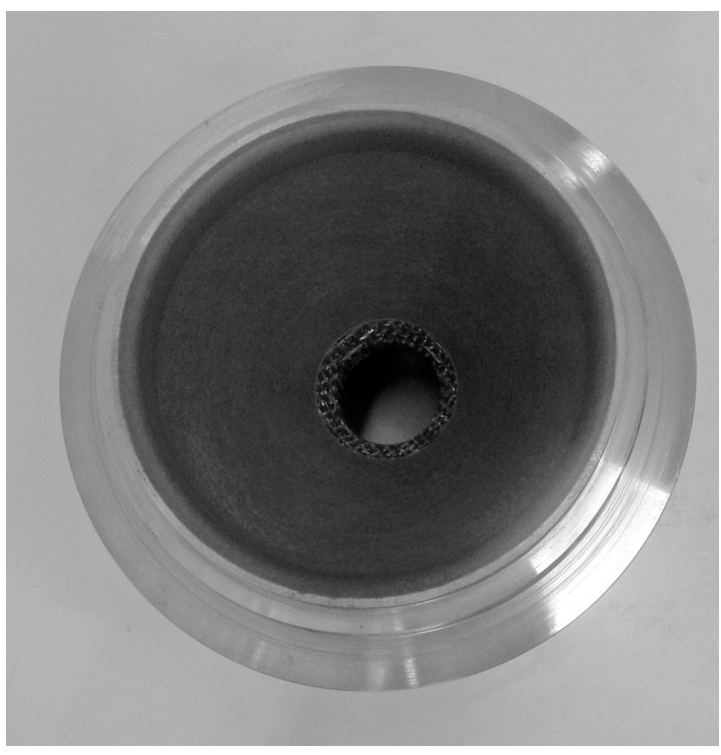

Рис. 16. Механическая обработка внутреннего теплозащитного покрытия сопла
- Диаметр критического сечения;

- Диаметр входного сечения по газу;

- Общая длина сопла;

- Macca

После изготовления экспериментальных сопел были проведены огневые стендовые испытания. Результаты испытаний показали, что сопло, вкладыш критического сечения которого изготовлен из материала на основе углеродной ткани и войлока, из-за термического удара на 1,15 секунде начал разрушаться, так как материал вкладыша имеет большой коэффициент теплопроводности и расположение слоев выполнено параллельно потоку. Испытание сопла, вкладыш критического сечения которого изготовлен из материала на основе нити углеродной конструкционной, прошло удачно. Результаты дефектации представлены в таблице 2.

Таблица 2

Результаты дефектации экспериментального сопла

\begin{tabular}{|l|c|c|c|c|}
\hline \multirow{2}{*}{ Наименование параметра } & \multicolumn{4}{|c|}{ Значения } \\
\cline { 2 - 5 } & по Кд & фактические & после ОСИ & унос \\
\hline Масса сопла, кг & 7,43 & 7,48 & 7,41 & 0,07 \\
\hline $\mathrm{D}_{\mathrm{a}}, \mathrm{Mм}$ & 120 & 119,53 & 120,5 & 0,97 \\
\hline $\mathrm{D}_{\text {кр }}, \mathrm{Mм}$ & 36 & 35,63 & 35,92 & 0,29 \\
\hline $\mathrm{L}_{\mathrm{c}}, \mathrm{Mм}$ & 220 & 220 & 221,2 & $+1,2$ \\
\hline
\end{tabular}




\section{4/2017 CXxponoryutcenn:TC}

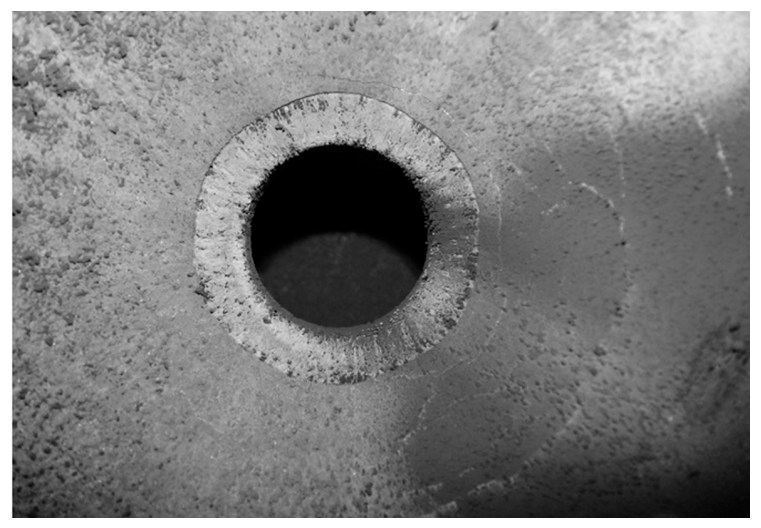

Рис. 17. Входная часть экспериментального сопла

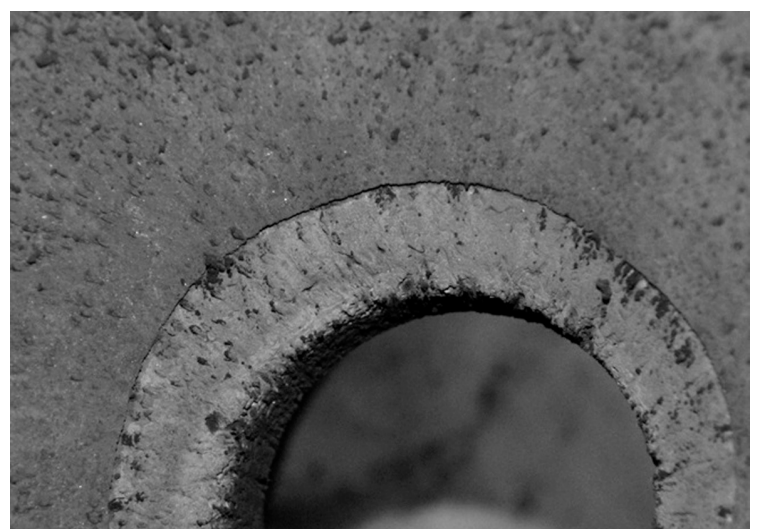

Рис. 18. Критическое сечение экспериментального сопла

Вид входной части, критического сечения и выходной части сопла, после проведения огневых стендовых испытаний, представлены на рисунках 17, 18 и 19 соответственно.

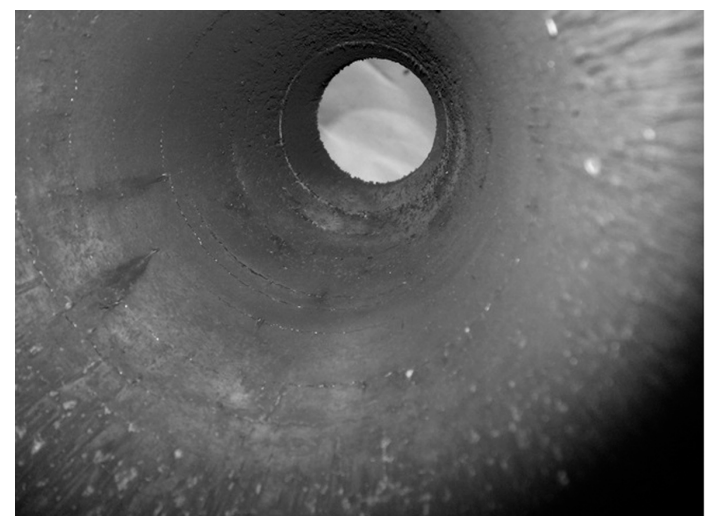

Рис. 19. Выходная часть экспериментального сопла

\section{Выводы}

В результате выполненных работ был осуществлен выбор необходимых неметаллических материалов и отработана технология изготовления модельных сопел, включая операции изготовления заготовок неметаллических деталей, механической обработки и клеесборочных работ, обеспечены требуемые значения выходных геометрических параметров и массы сопла в соответствии с требованиями КД.

\section{Литература}

[1] Фахрудинов И. Х., Котельников А. В. Конструкция и проектирование ракетных двигателей твердого топлива, Машиностроение, 1987.

[2] В.А. Борисов Конструирование основных узлов и систем ракетных двигателей. Электронный конспект лекций, 2011.

Kyslychnaya O. V., Maksymenko I. V., Brynza M. B., Potapov O. M.

Yuzhnoye, State-owned Design Office named after M. K. Yangel. Ukraine, Dnipro

\section{CONSTRUCTIVE - TECHNOLOGICAL FEATURES OF MANUFACTURING EXPERIMENTAL NOZZLES FOR A MODEL SOLID-FUEL ENGINE}

This article describes the technological features of manufacturing an experimental nozzle for a model engine. The design of the experimental nozzle is considered. The drawings of the components of the experimental nozzle are indicated. The main technological operations for manufacturing an experimental nozzle for a model engine are given. Particular attention is paid to the choice of the material and the way the parts are prepared. A comparison of the nozzle tests with different material of the critical section liners is given. [dx.doi.org/10.29010/081.7]

Keywords: experimental nozzle; collar blank; liner of critical section; mechanical restoration; assembly-pasting.

\section{References}

[1] I.Kh. Fakhrudinov and A.V. Kotelnikov. Design and design of rocket propulsion engines for solid fuels, Mechanical Engineering, 1987.

[2] V.A. Borisov Designing the main units and systems of rocket engines. Electronic lecture summary, 2011. 